\title{
Entrevista/Interview/Entrevista
}

Revista Brasileira de Extensão Universitária

v. 6, n. 2, p. 103-108 (2015)

e-ISSN 2358-0399

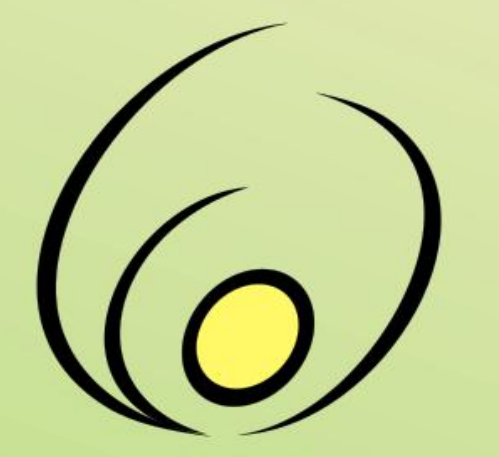

Fórum de

Pró-Reitores

de Extensão

das Instituições

Públicas de

Educação Superior

Brasileiras

\section{As ações de extensão universitária da modalidade}

\section{Rondon}

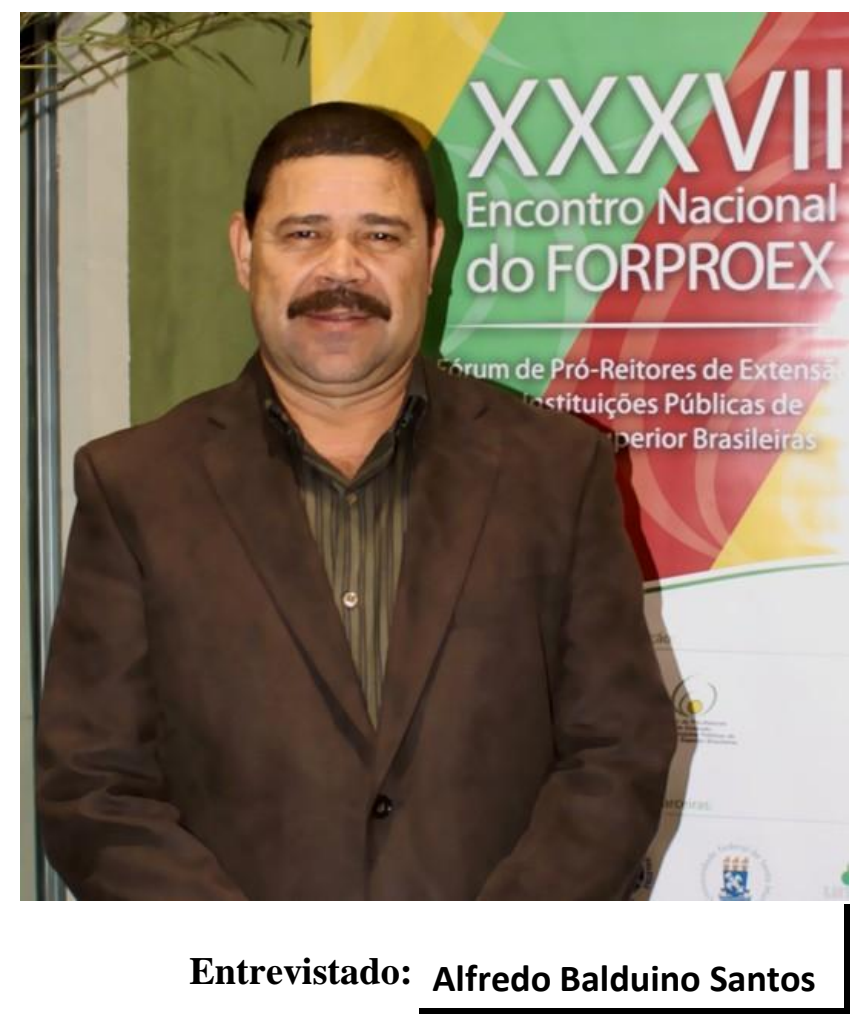

O projeto Rondon foi uma iniciativa criada durante o governo militar brasileiro, durante os anos 1970. Tinha como propósito promover a integração nacional, aproximando a juventude estudantil dos mais longínquos rincões do mapa brasileiro. A iniciativa foi inspirada no Marechal Cândido Rondon (1865-1958), ícone da integração nacional, conhecido sertanista brasileiro, que desbravou terras, comandou a instalação de linhas telegráficas, fazendo mapeamentos e estabelecendo os primeiros contatos com diversos povos indígenas. Suas iniciativas foram tão expressivas e impactantes para o país que seu nome ficou registrado na criação do Estado de Rondônia, em sua homenagem. 
Não obstante, o Projeto Rondon, enquanto iniciativa de extensão universitária promovida pelo governo militar e sob a coordenação do Exército Brasileiro, sempre foi alvo de críticas. Para o número 2 do volume 6 da Revista Brasileira de Extensão Universitária, convidamos o Professor Alfredo Balduino Santos, professor e reconhecido extensionista da Universidade do Estado de Santa Catarina, UDESC, para nos trazer, através desta entrevista, apontamentos sobre sua experiência na modalidade Rondon de extensão universitária.

\section{Revista Brasileira de Extensão Universitária: O} que é o Rondon enquanto ação extensionista, qual o seu conceito?

Alfredo Balduino Santos: Atualmente, podemos dizer que a atividade do Projeto Rondon é uma das ações mais duradouras de extensão, junto com os Centros de Referências da década de 60, e passou por momentos totalmente diferentes, desde a sua concepção na década de 70 , e a partir de 2005, quando foi retomado. Neste período, década de 70, era uma atividade voltada para o lado assistencialista. Hoje, em algumas IES Brasileiras, as questões sobre formação de pessoas são tratadas de modo mais acadêmico, saindo desta proposta assistencialista. Então, posso afirmar que o Projeto Rondon, pelo pouco conhecimento e vivência que possuímos da Extensão Universitária Brasileira, hoje apresenta ações acadêmicas, pautadas no conhecimento científico, em diálogo com o conhecimento empírico, por vezes ainda não reconhecidas por alguns ministérios. [Porém,] com certeza reúne, na sua organização, dependendo de cada Instituição de Ensino Superior (IES), ações totalmente voltadas para as áreas da extensão universitária brasileira. $\mathrm{O}$ que quer dizer, o projeto Rondon não é invenção de qualquer outra coisa, que não a Extensão Universitária Brasileira saindo dos seus muros para uma ação de grande proporção, chamada Projeto Rondon e, que poderia ter qualquer outro nome.

RBEU: O Rondon nasceu no âmbito da Ditadura Militar, os objetivos originais se mantém? Como se fundamenta o Rondon hoje?
ABS: Justamente, nesta questão respondemos um pouco mais sobre a primeira. Quem olha o Projeto Rondon e o próprio nome Rondon, que remete ao Marechal Cândido Rondon, acredita que a criação deste projeto se deu por meio do governo militar, mas o que ocorreu na verdade, foi uma proposta de um professor da então Universidade Estadual da Guanabara, hoje a UERJ [Universidade do Estado do Rio de Janeiro], professor Wilson Choeri, que, num evento organizado pelo exército, propôs que os acadêmicos das IES pudessem ter um conhecimento de brasilidade, assim como era oferecido aos alunos oficiais [do exército] daquele período. Assim, podemos afirmar que o professor Wilson Choeri, foi um grande estrategista, considerando o que era possível naquele momento. Por outro lado, para quem já tem uma leitura do Projeto Rondon no Brasil, e no meu trabalho de dissertação do mestrado sobre extensão universitária ${ }^{1}$ também se pode observar que quem trouxe essa provocação para as Universidades foi, então, o professor Wilson Choeri da Universidade Estadual da Guanabara, que faleceu em agosto de 2013. Professor esse que tive o prazer de conhecer e ouvir a sua história e a do Projeto Rondon, e de como ele provocou os militares, convencendo-os, para que isso acontecesse no Brasil. O professor Wilson relatou que, em um determinado momento, quando foi convidado para uma palestra destinada aos cadetes e alunos oficiais, ele percebeu que os alunos oficiais saíam para incursões no Brasil, a fim de obter um conhecimento de Brasil e propôs para o governo na época, governo militar, que isso também pudesse acontecer aos acadêmicos das Universidades Públicas Brasileiras. Portanto, isso ocorreu na década de 70 e recebeu o nome de Projeto Rondon por conta do Marechal Cândido Rondon, que tinha o lema de não usar armas e de chegar aonde chegou 
através da comunicação. A partir deste momento, começou-se a trabalhar a questão do Projeto Rondon, trazida por professores da Universidade Estadual de Guanabara, que saíram em 1967 na sua primeira incursão. Após um período de interrupção, o Projeto Rondon retorna em 1989, com o governo Fernando Henrique Cardoso, com outro nome, de Universidade Solidária, que era algo muito mais da [primeira dama] Ruth Cardoso, do que do governo em si. Em 2005 a União Nacional dos Estudantes pede a retomada desse trabalho, com o nome de Projeto Rondon. Então, nos dois momentos ele acontece com uma chamada e a provocação das universidades brasileiras. Diante disso, sugiro que retomemos o entendimento de que o Projeto Rondon não seja uma coisa de milico e/ou de militares. O Projeto Rondon é uma grande ação de extensão em rede, das universidades brasileiras, com a organização do Ministério da Defesa. Na retomada, foram reunidos alguns ministérios e o MEC também foi convidado, porém participou de uma forma não muito efetiva, ficando o Ministério da Defesa com a responsabilidade de fazer o contato das cidades e o deslocamento com as pessoas. $\mathrm{Na}$ verdade, considero que esta organização procede, se considerarmos que este Ministério conhece tudo de Brasil, tinha e tem recursos para esta demanda. Lamento a ausência do MEC nesse processo, que a meu ver, seria quem deveria realizar a gerência pedagógica desse projeto dentro de alguns de seus departamentos. Faço essa observação, tomando por parâmetro a nossa experiência na UDESC, com o Núcleo Extensionista Rondon (NER) que, em parceria com as prefeituras, na qual temos organizado, em Santa Catarina, propostas inspiradas no Projeto Rondon, e que têm sido bem aceitas por estes municípios, revelando-se como ações exitosas de extensão universitária.

RBEU: Conte-nos um pouco sobre a sua experiência e trajetória em Rondon e quando você começou.

ABS: Quem me conhece acha que eu participo do Rondon desde 1970... [risos]. A minha história com o Rondon começa em 2007, quando, como professor da UDESC, escrevi uma proposta para o Ministério da Defesa e fomos contemplados. Assim, em 2008 eu viajei para o Piauí, no município de
Campo Largo. A partir desta experiência, que foi muito boa e proveitosa, começamos a coordenar o Projeto Rondon na UDESC. Em 2010, em um encontro de extensão, onde estavam presentes eu e os professores Paulinho Cardoso (Pró-reitor de Extensão, Cultura e Comunidade na época), Marcos Tomasi, (Planejamento) Antonio Heronaldo (Vice Reitor), Prof. Antônio Carlos dos Anjos Filho (Prof. convidado) entre outros. Fomos provocados, pelo então, Reitor Sebastião Iberes Lopes Melo: "se vocês fizeram essa atividade de extensão fora e bem feita, por que não fazer em Santa Catarina?" Surgiu então, a proposta de organizar atividade semelhante no estado de Santa Catarina e essa foi a experiência que adquirimos ao longo desse tempo. A minha experiência com o Projeto Rondon, participando de operações organizadas pelo Ministério da Defesa, me ensinou bastante. Participamos de uma reunião dos professores do Projeto Rondon ${ }^{2}$, quando íamos conhecendo as pessoas que faziam o Projeto Rondon no país, conhecendo um pouco dos núcleos que foram surgindo em torno desse trabalho, portanto a minha experiência vem do Ministério da Defesa, do MEC e das parcerias que foram se estabelecendo a partir da Universidade de Brasília ao longo dos primeiros anos de participação. Parcerias estas que foram se intensificando e aumentando ao longo deste período.

\section{A maioria de nossos professores entende que são contratados para a sala de aula, incluindo muitas vezes a pesquisa, deixando a extensão de lado, desconsiderando-a como espaço de criação do conhecimento a partir da sociedade.}

RBEU: E já falando dá experiência da UDESC que você menciona, o que ela acrescenta, se é que modifica alguma coisa em relação a proposta coordenada pelo Ministério da Defesa e o que vocês conseguiram avançar nessa proposta mais regional.

ABS: Existe um 'filósofo' que eu gosto muito de escutar, nosso contemporâneo Silvio Santos [nome 
artístico de Senor Abravanel], ele conta em uma de suas falas que o que ele faz hoje com a televisão não é ele que cria, ele melhora algo que já acontece. Então, o Projeto Rondon, que todo mundo acha que é militar, acabou por inspirar a nossa proposta na UDESC, ao sermos desafiados a organizá-lo, como já mencionei, no estado de Santa Catarina. Nessa caminhada nós aprendemos com o Ministério da Defesa, mais especificamente no início da caminhada, ao acompanhar os professores nas reuniões, e agradeço aos coronéis e generais com os quais tivemos essa experiência. Igual agradecimento aos professores com os quais tivemos o prazer de dividir tal experiência. A partir desse aprendizado de como fazer, nós pautamos essa atividade para o estado de Santa Catarina. Como nós organizamos? Inicialmente, por meio de uma conversa com as Secretarias de Desenvolvimento Regionais ${ }^{3}$ - SDRs, para as quais a UDESC propõe algumas ações de extensão, como oficinas a partir das áreas temáticas da extensão universitária brasileira. No que consideramos ter melhorado? As atividades desenvolvidas em nossas "operações", são desenvolvidas por um grupo interdisciplinar de acadêmicos de todas as universidades parceiras em um determinado município. Até o momento, temos tido a participação do Instituto Federal de Santa Catarina, a Universidade Federal da Fronteira Sul, Universidade Estadual de Ponta Grossa, a Universidade Estadual de Roraima, a Universidade Federal de Ciências e Saúde de Porto Alegre, acadêmicos da [Universidade Federal do Rio Grande do Sul -] UFRGS, acadêmicos da Universidade Federal de Santa Catarina, que vêm participando conosco, não de forma separada em cada instituição, mas sim fazendo parte do grupo. $\mathrm{E}$ isso fez com que consolidássemos, por meio da extensão universitária, a proposta de intercâmbio [com as comunidades] no país, com um trabalho interdisciplinar exitoso, a considerar os depoimentos dos próprios acadêmicos ${ }^{4}$, diferente de uma proposta focada somente em uma determinada área [do conhecimento]. Então, estamos conseguindo fazer com que essa ação se torne, realmente uma ação interdisciplinar o que, para a formação de pessoas, é o mais importante. A importância do que nós conseguimos foi fazer com que essa ação perdesse aquela característica de ir lá e dar o "peixe" e pronto, e através dessa proximidade com as outras Universidades que tivemos tudo isso, por isso são experiências positivas. Hoje, no país todo, somente a UDESC, e depois a UEPG, a partir deste ano de 2015, inspirada na UDESC, é que fazem. Outras universidades estão fazendo o mesmo movimento, ou seja, o Projeto Rondon local, como a UEPG já mencionada, a UESC que está se organizando para tal, e a Estadual de Roraima que já organizou uma operação. Contudo, ainda se fala muito pouco sobre o assunto, sendo esse pouco muito atrelado ao paradigma assistencialista, impresso na origem do Projeto Rondon. Dessa forma, com poucas evoluções em sua execução. Agora, na nossa participação com a [operação coordenada pela] UEPG em julho é que nós vamos ver até onde eles conseguiram também dar um passo para que essa ação fosse da UEPG e não do Ministério da Defesa. A idéia é fazer com que a instituição assuma essa ação, assim como a UDESC assumiu, e que inclusive já coloca em seu vídeo institucional a ação do Projeto Rondon.

Se ensina muito mais aprendendo do que fazendo e levando, e essa troca de conhecimento entre comunidade, acadêmicos, professores e servidores, faz com que tenhamos uma ação mais completa da Universidade brasileira (...), proporcionando aos acadêmicos perceberem que o conhecimento que eles trazem do ensino, em diálogo com o conhecimento popular, pode redimensioná-lo, (re)elaborá-lo.

RBEU: Falando nessas ações regionais que as instituições assumem, como você vê o impacto do Rondon na comunidade universitária, docentes, servidores e alunos.

ABS: A Extensão Universitária com a qual a gente pactua, para quem faz, para quem gosta, é fácil. Mas essa mesma extensão exige trabalho e, infelizmente, a maioria de nossos professores entende que são 
contratados para a sala de aula, incluindo muitas vezes a pesquisa, deixando a extensão de lado, desconsiderando-a como espaço de criação do conhecimento a partir da sociedade. Então, não é o Projeto Rondon, é a Extensão Universitária brasileira que passa por isso. Assim, temos ainda poucos professores atuando, mas temos muitos técnicos coordenadores de equipes na coordenação local das ações. Esclarecendo que temos coordenação geral e coordenação da equipe local. Temos professores coordenadores, inclusive diretores gerais e de extensão dos centros, participando, mas há uma resistência bastante forte por parte dos nossos dos professores. Quanto aos acadêmicos, esta atividade é para a sua formação, na sua totalidade como muitos mencionam, e é mais significativa do que muitas disciplinas. Formação enquanto cidadão, formação enquanto pessoa para a sociedade e com a sociedade. Não simplesmente uma máquina formatada apenas na sua área, sem saber o que é a sociedade e que é parte desse grupo social, que é o que temos acompanhado muitas vezes, sendo inclusive, tema de avaliação por parte dos acadêmicos que tem tido essa vivência acadêmica, a extensão universitária. Costumamos brincar com estes acadêmicos usando uma situação que é mais comum do que imaginamos, a epilepsia: uma pessoa em crise epilética tem os sintomas de uma pessoa bêbada, meio grogue e muitas vezes deixamos uma pessoa em crise epilética se debatendo e por vezes, mesmo morrer porque achamos que a pessoa está bêbada por não termos vivências acadêmicas que nos aproximam da sociedade. Assim, esta e tantas outras situações, são oportunidades que podemos trabalhar isso com os meninos e com as meninas, é vivenciando, levando para a rua, rompendo essa barreira que há entre a Universidade e a comunidade. É aquela história que o nosso velho amigo Paulo Freire falava, e está aí pra todos, o ensino e a educação são via de mão dupla, tanto se aprende quanto se ensina. Aliás, se ensina muito mais aprendendo do que fazendo e levando, e essa troca de conhecimento entre comunidade, acadêmicos, professores e servidores, faz com que tenhamos uma ação mais completa da Universidade brasileira, Universidade catarinense, fazendo com que ocorra essa interlocução entre ensino, pesquisa e extensão, proporcionando aos acadêmicos perceberem que o conhecimento que eles trazem do ensino, em diálogo com o conhecimento popular, pode redimensioná-lo, (re)elaborá-lo inclusive. Então, podemos afirmar que a extensão universitária é uma ação completa aberta a interlocução entre o ensino e a pesquisa.

\section{Podemos afirmar que esta atividade de $\mathbf{1 0}$ dias, além de ser, estrategicamente, um excelente laboratório para os acadêmicos e também para nós, servidores, é potencialmente espaço de aproximações necessárias com as comunidades, que se consolida com o estabelecimento de convênios, além de possibilitar a população que conheça um pouco da universidade.}

RBEU: E o impacto na comunidade? Uma das críticas ao Rondon é seu caráter efêmero. Até que ponto o encontro com algumas comunidades em uma ou duas semanas são momentos isolados, ou eles têm continuidade?

ABS: Ao avaliarmos o caráter efêmero atribuído à atividade do Rondon, temos que avaliar também tantas outras atividades nas IES, às quais podemos atribuir o mesmo caráter, como por exemplo, uma determinada disciplina que nunca disse a que veio, nunca justificou a sua razão na grade curricular de qualquer curso, exceto pela carga horária total do curso, muitas atividades de pesquisa, onde o pesquisador pesquisa para ele e somente para ele, e até mesmo na extensão, quantas atividades são aprovadas apenas para o seu coordenador completar seu plano de trabalho - felizmente, nesse caso isso já tenta combater, mas sabemos que já ocorreu muito. Então, considero que o caráter efêmero, neste caso, e especialmente no que refere ao Rondon, não podemos esquecer o que já mencionamos nesta entrevista, [está ligado] à falta de conhecimento das pessoas sobre a origem do projeto e, por isso, à resistência das pessoas. Se considerarmos uma 
atividade de extensão que vai às diferentes comunidades a dizer, enquanto universidade, a que estamos, quem somos, a quem servimos, só pro isso, a meu ver já justificaria o projeto. Quando observamos, em nosso estado [de Santa Catarina], por exemplo, aumentada a procura dos nossos cursos, no vestibular, por parte de jovens do interior, o que antes do Projeto Rondon não faziam, por desconhecer o caráter público da universidade, isso por si só, já nos justifica. No entanto, o trabalho com o projeto tem mostrado que se estabelece um contato com estes municípios no sentido de estabelecimento e consolidação de parcerias, com a efetivação de convênios técnicos científicos, proporcionando a continuidade das ações em projetos de formação continuada de professores, saúde e setores diversos, bem como outras atividades. Ainda, se considerarmos que $17 \%$ dos jovens de 18 a 24 anos estudam em universidade públicas federais e estaduais, então são $17 \%$ da sociedade brasileira catarinense que tem que devolver de alguma forma aquilo que é investido, para que eles possam sair dali profissionais em alguma área. Deste modo, podemos avaliar que, quando estes municípios percebem a possibilidade de parceria com a Universidade, como temos hoje ações a partir do Projeto Rondon, em vários municípios, podemos afirmar que esta atividade de 10 dias, além de ser, estrategicamente, um excelente laboratório para os acadêmicos e também para nós, servidores, é potencialmente espaço de aproximações necessárias com as comunidades, que se consolida, como já mencionado, com o estabelecimento de convênios, além de possibilitar a população que conheça um pouco da universidade.
Esta entrevista foi mediada pelo professor Geraldo

Ceni Coelho (cenicoelho@gmail.com), da Universidade Federal da Fronteira Sul - UFFS, campus Chapecó, Santa Catarina, editor da Revista Brasileira de Extensão Universitária - RBEU, durante o $37^{\circ}$ Encontro Nacional do FORPROEX, Fórum de Pró-Reitores de Extensão das Instituições Públicas de Ensino Superior Brasileiras, em Gramado, maio de 2015.

\section{Notas}

1 SANTOS, A. B. Extensão universitária como viabilizadora de políticas públicas: a visão de acadêmicos da UDESC. Dissertação de Mestrado em Gestão de Políticas Públicas, Universidade do Vale do Itajaí - UNIVALI, Itajaí, Brasil, 2012.

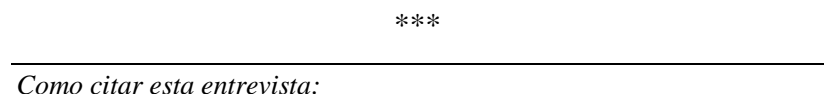

Como citar esta entrevista:

SANTOS, A. B As ações de extensão universitária da modalidade Rondon. Entrevista concedida a Geraldo Ceni Coelho. Revista Brasileira de Extensão Universitária, v. 6, n. 2, p. 103-108, 2015. Disponível em: <https://periodicos.uffs.edu.br/index.php/RBEU/article Liew/3098/pdf $>$ 